Dermatology 2011;222:138-139

DOI: $\underline{10.1159 / 000323006}$

\section{Will Immunoglobulin Therapy of Autoimmune Blistering Skin Diseases Survive the New Financial Management of Inpatients?}

Peter J. Späth ${ }^{\mathrm{a}}$, Thomas Hunziker ${ }^{\mathrm{b}}$

Departments of a Pharmacology and ${ }^{b}$ Dermatology, Medical Faculty, University of Berne, Berne, Switzerland

\section{Key Words}

Immunoglobulin $\cdot$ Autoimmune blistering disease

Autoimmune blistering mucocutaneous diseases are rare but may be associated with high morbidity and a significant mortality rate. Treatment is cumbersome and the therapeutic armamentarium is limited. Mainly in pemphigus, high-dose systemic corticosteroids are still the first-line and cornerstone treatment. Due to long-term adverse effects, 'steroid-sparing' adjuvants are widely used, mostly without having proven their clinical efficacy in randomized controlled studies. Intravenous immunoglobulin (IVIG), however, has been evaluated in several randomized controlled trials [1,2], and the levels and recommendations for evidence-based-medicine treatment of various autoimmune blistering skin diseases were listed recently [3]. Use of IVIG is attractive because of its low adverse event profile, and its use in children has also been addressed $[4,5]$.

IVIG therapy is expensive and usually needs inpatient health care professional assistance. In the setting of the diagnosis-related group type of financial management in hospitals there is some concern that patients unresponsive or showing severe adverse effects to the first-line therapy might be treated below optimum by avoiding the use of IVIG, neglecting the fact that in the long run, such suboptimal treatment might finally cause health care costs above those of IVIG therapy. Switching over to a semiambulatory setting, dispensing with postinfusion surveillance in these often severely ill patients might infringe on ethical standards. To overcome this dilemma, outpatient treatment with subcutaneous IgG (SCIG) might provide the solution.

Subcutaneous application of an immunoglobulin concentrate to patients with hypo- or agammaglobulinemia due to primary immunodeficiency (PID) has first been reported in 1952 [6]; the idea has been taken up in 1980 again [7], and treatment schedules were elaborated in the 90s $[8,9]$. In the first years of the new millennium, prospective controlled studies comparing intravenous and subcutaneous applications of immunoglobulin concentrates were performed $[10,11]$. Thereby, the safety and efficacy of SCIG in previously untreated PID patients, including children, was high $[12,13]$. Today, several immunoglobulin concentrates at strengths of 10 or $16 \%$ are registered for subcutaneous application in PID patients. The running marketing authorization process in the EU member states and Switzerland will soon make a $20 \%$ SCIG available. This preparation will enable to apply considerable doses at relatively low volumes (up to $0.5 \mathrm{~g} /$ single site of injection; application at several sites possible) [14]. Last but not least, from a social insurance's perspective, evaluation of IVIG versus SCIG showed a potential for cost saving when using SCIG replacement therapy $[15,16]$.

According to a widely accepted belief, a hallmark of immunomodulation and control of inflammation in chronic autoimmune diseases by IVIG is a repeated, rapid enhancement of IgG in the circulation to levels considerably above the norm. The total amount applied per treatment is $1-2 \mathrm{~g}$ IgG/ $\mathrm{kg}$ body weight over 2-5 days. Indeed, maintenance of IgG levels close to or within the norm was insufficient in preventing the development of immune thrombocytopenic purpura [17-19]. The question remains whether for immunomodulation SCIG, which does not induce the high peak levels, can replace IVIG, at least in some of the chronic inflammatory and/or autoimmune conditions responsive to IVIG. Actually, there are valuable hints that SCIG could indeed be immunomodulatory and anti-inflammatory in neurological conditions such as multifocal motor neuropathy [20-23] or chronic inflammatory demyelinating polyradiculoneuropathy [23-28] as well as dermatomyositis $[29,30]$. Moreover, there is one publication of successful SCIG therapy in a patient with severe epidermolysis bullosa acquisita [31]. To the best of our knowledge, a 'steroid-sparing' effect of SCIG has not yet been studied in other autoimmune blistering skin diseases. To keep adjuvant immunoglobulin therapy available for severe cases, we propose a clinical trial in patients with recalcitrant pemphigus vulgaris assessing the 'steroid-sparing effect' of SCIG in a way similar to that of Amagai et al. [1].

\section{Disclosure Statement}

P.J.S. is consultant to the Research and Development Department of CSL Behring, Berne, and has acted as invited speaker for CSL Behring. T.H. has no conflict of interest.

\section{KARGER}

(C) 2011 S. Karger AG, Basel

Fax +4161306 1234

E-Mail karger@karger.ch

www.karger.com
Accessible online at: www.karger.com/drm 


\section{References}

1 Amagai M, Ikeda S, Shimizu H, Iizuka H, Hanada K, Aiba S, Kaneko F, Izaki S, Tamaki K, Ikezawa Z, Takigawa M, Seishima M, Tanaka T, Miyachi Y, Katayama I, Horiguchi Y, Miyagawa S, Furukawa F, Iwatsuki K, Hide M, Tokura Y, Furue M, Hashimoto T, Ihn H, Fujiwara S, Nishikawa T, Ogawa H, Kitajima Y, Hashimoto K: A randomized double-blind trial of intravenous immunoglobulin for pemphigus. J Am Acad Dermatol 2009;60:595-603.

-2 Arnold DF, Burton J, Shine B, Wojnarowska F, Misbah SA: An 'n-of-1' placebo-controlled crossover trial of intravenous immunoglobulin as adjuvant therapy in refractory pemphigus vulgaris. Br J Dermatol 2009; 160:1098-1102.

-3 Enk A, European Dermatology Forum Guideline Subcommittee, Fierlbeck G, French L, Girolomoni G, Hertl M, Jolles S, Joly P, Karpati S, Messer G, Meurer M, Steinbrink K, Stingl G, Volc-Platzer B, Zillikens D, Aberer W, Bagot M, Braathen L, Chimenti S, Diaz-Perez JL, Hegyi V, Kemény L, Korting HC, Murphy G, Neumann M, Ormerod T, Ranki A, Wojnarowska F, Sterry W: Guidelines on the use of high-dose intravenous immunoglobulin in dermatology. Eur J Dermatol 2009;19: 90-98.

-4 Asarch A, Razzaque AA: Treatment of juvenile pemphigus vulgaris with intravenous immunoglobulin therapy. Pediatr Dermatol 2009;26: 197-202.

5 Nanda A, Nanda M, Dvorak R, Al-Sabah H, Alsaleh QA: Bullous pemphigoid (BP) in an infant complicated by tuberculous meningoencephalitis. Int J Dermatol 2007;46:964-966.

6 Bruton OC: Agammaglobulinemia. Pediatrics 1952;9:722-728.

7 Berger M, Cupps TR, Fauci AS: Immunoglobulin replacement therapy by slow subcutaneous infusion. Ann Intern Med 1980;93:55-56.

-8 Gardulf A, Hammarström L, Smith CIE: Home treatment of hypogammaglobulinaemia with subcutaneous gammaglobulin by rapid infusion. Lancet 1991;338:162-166.

-9 Gardulf A, Andersen V, Björkander J, Ericson D, Froland SS, Gustafson R, Hammarström L, Jacobsen MB, Jonsson E, Moller G: Subcutaneous immunoglobulin replacement in patients with primary antibody deficiencies: safety and costs. Lancet 1995;345:365-369.

10 Chapel HM, Spickett GP, Ericson D, Engl W, Eibl MM, Björkander J: The comparison of the efficacy and safety of intravenous versus subcutaneous immunoglobulin replacement therapy. J Clin Immunol 2000; 20:94-100.

11 Gardulf A, Nicolay U, Asensio O, Bernatowska E, Bock A, Carvalho BC, Granert C, Haag S, Hernandez D, Kiessling P, Kus J, Pons J, Niehues T, Schmidt S, Schulze I, Borte M: Rapid subcutaneous IgG replacement therapy is effective and safe in children and adults with primary immunodeficiencies - a prospective, multi-national study. J Clin Immunol 2006;26:177-185.

12 Gardulf A, Nicolay U, Math D, Asensio O, Bernatowska E, Bock A, Costa-Carvalho BT, Granert C, Haag S, Hernandez D, Kiessling P, Kus J, Matamoros N, Niehues T, Schmidt S, Schulze I, Borte M: Children and adults with primary antibody deficiencies gain quality of life by subcutaneous IgG self-infusions at home. J Allergy Clin Immunol 2004;114:936-942.

13 Ochs HD, Gupta S, Kiessling P, Nicolay U, Berger M: Safety and efficacy of self-administered subcutaneous immunoglobulin in patients with primary immunodeficiency diseases. J Clin Immunol 2006;26: 265-273.

14 Hagan JB, Fasano MB, Spector S, Wasserman RL, Melamed I, Rojavin MA, Zenker O, Orange JS: Efficacy and safety of a new $20 \%$ immunoglobulin preparation for subcutaneous administration, IgPro20, in patients with primary immunodeficiency. J Clin Immunol 2010;30:734745 .

15 Beaute J, Levy P, Millet V, Debre M, Dudoit Y, Le Mignot L, Tajahmady A, Thomas C, Suarez F, Pellier I, Hermine O, Aladjidi N, Mahlaoui N, Fischer A: Economic evaluation of immunoglobulin replacement in patients with primary antibody deficiencies. Clin Exp Immunol 2010;160: 240-245.
16 Högy B, Keinecke HO, Borte M: Pharmacoeconomic evaluation of immunoglobulin treatment in patients with antibody deficiencies from the perspective of the German statutory health insurance. Eur J Health Econ 2004;50:24-29.

17 Heath J, Goldman FD: Idiopathic thrombocytopenic purpura in a boy with ataxia telangiectasia on immunoglobulin replacement therapy. J Pediatr Hematol Oncol 2010;32:e25-e27.

18 Michel M, Chanet V, Galicier L, Ruivard M, Levy Y, Hermine O, Oksenhendler E, Schaeffer A, Bierling P, Godeau B: Autoimmune thrombocytopenic purpura and common variable immunodeficiency: analysis of 21 cases and review of the literature. Medicine (Baltimore) 2004 83:254-263.

19 Wang J, Cunningham-Rundles C: Treatment and outcome of autoimmune hematologic disease in common variable immunodeficiency (CVID). J Autoimmun 2005;25:57-62.

20 Eftimov F, Vermeulen M, de Haan RJ, van den Berg LH, van Schaik IN: Subcutaneous immunoglobulin therapy for multifocal motor neuropathy. J Peripher Nerv Syst 2009;14:93-100.

21 Harbo T, Andersen H, Hess A, Hansen K, Sindrup SH, Jakobsen J: Subcutaneous versus intravenous immunoglobulin in multifocal motor neuropathy: a randomized, single-blinded cross-over trial. Eur J Neurol 2009; 16:631-638.

22 Harbo T, Andersen H, Jakobsen J: Long-term therapy with high doses of subcutaneous immunoglobulin in multifocal motor neuropathy. Neurology 2010;75:1377-1380.

23 Köller H, Schroeter M, Feischen H, Hartung HP, Kieseier BC: Subcutaneous self-infusions of immunoglobulins as a potential therapeutic regimen in immune-mediated neuropathies. J Neurol 2006;253:15051506.

24 Kuitwaard K, van Doorn PA: Newer therapeutic options for chronic inflammatory demyelinating polyradiculoneuropathy. Drugs 2009;69: 987-1001.

25 Lee DH, Linker RA, Paulus W, Schneider-Gold C, Chan A, Gold R: Subcutaneous immunoglobulin infusion: a new therapeutic option in chronic inflammatory demyelinating polyneuropathy. Muscle Nerve 2008;37:406-409.

26 Sladky JT: What is the best initial treatment for childhood chronic inflammatory demyelinating polyneuropathy: corticosteroids or intravenous immunoglobulin? Muscle Nerve 2008;38:1638-1643.

27 Van Schaik IN: What's new in chronic inflammatory demyelinating polyradiculoneuropathy in 2007-2008? J Peripher Nerv Syst 2008;13: 258-260.

28 Woodall A, Jones S: Switching to home-based SCIg for multifocal motor neuropathy (MMN). Br J Nurs 2010;19:S27-S31.

29 Schleinitz N, Jean E, Benarous L, Mazodier K, Figarella-Branger D, Bernit E, Veit V, Kaplanski G, Harle JR: Subcutaneous immunoglobulin administration: an alternative to intravenous infusion as adjuvant treatment for dermatomyositis? Clin Rheumatol 2008;27:1067-1068.

30 Danieli MG, Pettinari L, Moretti R, Logullo F, Gabrielli A: Subcutaneous immunoglobulin in polymyositis and dermatomyositis: A novel application. Autoimmun Rev 2010 Sep 19, Epub ahead of print.

31 Tayal U, Burton J, Dash C, Wojnarowska F, Chapel H: Subcutaneous immunoglobulin therapy for immunomodulation in a patient with severe epidermolysis bullosa acquisita. Clin Immunol 2008;129:518-519.

Peter J. Späth

Department of Pharmacology, University of Berne

Friedbühlstrasse 49

CH-3010 Bern (Switzerland)

E-Mail peter.spaeth@pki.unibe.ch 